OPEN ACCESS

Edited by:

Nicola Banwell,

University of Lausanne, Switzerland

Reviewed by:

Pedro Roberto Jacobi,

University of São Paulo, Brazil

*Correspondence:

Anne Gaspers

anne.gaspers@sintef.no

Specialty section:

This article was submitted to

Climate Services,

a section of the journal

Frontiers in Climate

Received: 08 December 2021

Accepted: 01 February 2022

Published: 25 February 2022

Citation:

Gaspers A, Oftebro TL and Cowan E (2022) Including the Oft-Forgotten: The Necessity of Including Women and Indigenous Peoples in

Nature-Based Solution Research.

Front. Clim. 4:831430

doi: 10.3389/fclim.2022.831430

\section{Including the Oft-Forgotten: The Necessity of Including Women and Indigenous Peoples in Nature-Based Solution Research}

\author{
Anne Gaspers*, Thea Lurås Oftebro and Emily Cowan \\ SINTEF Ocean, Department of Climate and Environment, Trondheim, Norway
}

Nature-based Solutions (NbS) are a priority area for the European Commission. The European Union (EU) will fund projects on NbS under Horizon Europe, the EU's framework program for research and innovation (2021-2027). We argue that the Commission needs to fund more projects that actively include local communities in the development and implementation of NbS. Specifically, the Commission needs to fund projects that include two oft-forgotten stakeholder groups: women and indigenous peoples. The literature demonstrates that success of $\mathrm{NbS}$ is dependent on the inclusion of a variety of stakeholders and that indigenous peoples and women and girls are critically important stakeholders. As the inclusion of these stakeholders is vital to the success of $\mathrm{NbS}$, funding projects that specifically include these stakeholders will help the EU to achieve two important policy goals: the goal to provide evidence for $\mathrm{NbS}$ and the goal to advance the development, uptake and upscale of $\mathrm{NbS}$.

Keywords: climate change, disaster resilience, European Union policy, Horizon Europe, indigenous peoples, Nature-based Solutions, stakeholder integration, women and girls

\section{INTRODUCTION}

Climate change is affecting every inhabited region of our world (IPCC, 2021, p. 10), and we need to take action. According to the European Commission (EC), Nature-based Solutions (NbS) are one way to help tackle environmental challenges (European Commission, 2022b), such as fires, floods, hurricanes, landslides, and droughts. Scientists predict, if properly delivered, $\mathrm{NbS}$ can provide 37 per cent of the cost-effective $\mathrm{CO}_{2}$ mitigation that is needed through 2030 (Griscom et al., 2017). A relatively new term in modern-day science, NbS are defined in various ways, but two commonly cited definitions are that of the EC and the International Union for the Conservation of Nature (IUCN) (Ruangpan et al., 2020; Seddon et al., 2021; Xie, 2021). Defined by the EC, NbS are "Solutions that are inspired and supported by nature, which are cost-effective, simultaneously provide environmental, social, and economic benefits and help build resilience. Such solutions bring more, and more diverse, nature and natural features and processes into cities, landscapes and seascapes, through locally adapted, resource-efficient, and systemic interventions" (European Commission, 2022a). The IUCN gives a similar definition, defining NbS as "actions to protect, sustainably manage and restore natural and modified ecosystems in ways that address societal challenges effectively and adaptively, to provide both human well-being and biodiversity benefits" (IUCN, n.d). They go on to say that NbS "are underpinned by benefits that flow from healthy ecosystems and target major challenges like climate change, disaster risk reduction, food and water 
security, health and are critical to economic development" (IUCN, n.d). In short, NbS work with and enhance nature rather than working against it.

Due to their cross-cutting nature, NbS can address several of the United Nation's Sustainable Development Goals (SDGs) at once (Chausson et al., 2020; Ruangpan et al., 2020). SeifollahiAghmiuni et al. (2019), as cited in Ruangpan et al. (2020), give the example of wetland ecosystem services in Sweden, which can contribute to addressing SDGs 1 (no poverty), 2 (zero hunger), 3 (good health and well-being), 6 (clean water and sanitation), 7 (affordable and clean energy), 11 (sustainable cities and communities), 12 (responsible consumption and production), 13 (climate action), 14 (life below water), and, finally, 15 (life on land). In short, $\mathrm{NbS}$ are one of a multitude of solutions, which can help to solve-or at the very least lessen-the climate crisis and address the United Nation's SDGs.

The EC, since 2013, has given special attention to NbS (Faivre et al., 2017). Today, the EC has five policy goals when it comes to $\mathrm{NbS}$ : (1) to provide evidence for $\mathrm{NbS},(2)$ to improve framework conditions for $\mathrm{NbS}$ at the EU policy level, (3) to develop a European research and innovation community, (4) to advance the development, uptake, and upscale of innovative $\mathrm{NbS}$, and, finally, (5) to mainstream $\mathrm{NbS}$ in international research and innovation (European Commission, 2022b). The EC currently funds projects on $\mathrm{NbS}$ through the Horizon 2020 programme, and the EC will continue to fund projects on $\mathrm{NbS}$ through the Horizon Europe programme, which will run from 2021 until 2027 (European Commission, 2022b).

Since the European framework programme for research and innovation was first introduced in 1984, several significant steps have been taken to include a vast range of stakeholders in EC-funded projects. The first four programmes focused on the inclusion of industries and enterprises, while the fifth programme marked the shift toward focusing on issues and challenges faces by communities and citizens (Commission of the European Communities, 1996). The shift toward focusing on citizens was evident across the whole of the European Union (EU). In framework programmes six and seven, the EC took steps toward making civil society stakeholders of the programme (Warin and Delaney, 2020). During the eighth programme, Horizon 2020 and the current Horizon Europe programme (2021-2027), the EC pledged to make citizens key stakeholders and to have them take part in decision-making (European Commission, 2017).

Gender equality is a cross-cutting principle of Horizon Europe (European Commission, 2021a) and public bodies, research organizations, and higher education establishments from member states and associated countries are, for the first time, required to have a Gender Equality Plan (GEP) in order to access funding from the EU framework programme (European Commission, 2021b). Particular attention is given to the advisory boards, where there is a target of having 50 per cent women. Furthermore, there is also attention put toward having a gender equality among researchers involved in the projects. This is said to be taken into account as a ranking criteria if proposals are awarded the same evaluation score (European Commission, 2021b). Neither the strategic plan, nor the programme guide for Horizon Europe make explicit reference to indigenous peoples.
However, the strategic plan is focused on addressing the needs of vulnerable population groups (European Commission, 2021a). Nevertheless, the EU is giving attention to indigenous peoples. This is evident in the consultations with indigenous peoples (Service of Foreign Policy Instruments, 2020), the EC's support of establishing the Docip office in Brussels, which aims to facilitate collaboration between indigenous people and the EU institutions (Docip) ${ }^{1}$, and in the EU's Arctic Strategy, in which the EU pledges to include more indigenous people in Arctic decision-making (European Commission, 2021c).

Recently, the UN Climate Conference, COP26, drew attention to the important, yet often ignored, roles of women and indigenous peoples in addressing the climate crisis (United Nations Climate Change, 2021b; United Nations News, 2021). While previous UN Climate Conferences have also drawn attention to women and indigenous peoples (United Nations Climate Change, 2018a,b), we argue these stakeholders need to be included to a greater degree. Stakeholder engagement is especially important for research on $\mathrm{NbS}$, and women and indigenous peoples, specifically, are critical stakeholders. Therefore, projects funded under Horizon Europe focusing on $\mathrm{NbS}$ should work to better include local stakeholders in general and indigenous peoples and women and girls specifically. Funding projects that include these groups will help the EC to achieve at least two important policy goals: the goal to include stakeholders in Horizon Europe projects and the goal to advance the development, uptake, and upscale of $\mathrm{NbS}$. In the sections to follow, we highlight the importance of including local stakeholders, especially women and indigenous peoples, and we lay out guiding principles as well as best practices on how to include them in research projects on $\mathrm{NbS}$.

\section{WHY INCLUDING LOCAL STAKEHOLDERS IS IMPORTANT TO THE SUCCESS OF NbS RESEARCH}

Today, transdisciplinary science is becoming more prevalent, and there is a demand to ensure that research results have practical impacts. The social sciences are a way to include valuable data from stakeholders into research via workshops and interviews. This is where stakeholders have a pivotal role in scientific research. We use Freeman's definition of a stakeholder. Freeman defines stakeholders as “... any group or individual who can affect or is affected by the achievement of the organization's objectives" (Freeman, 1984, p. 46). We, therefore, argue that when it comes to NbS being implemented at the local level across Europe, stakeholders include all citizens of a given community. It is vital that stakeholders are involved in the solution finding process to increase support in the decision-making process. Including stakeholders can enhance knowledge transfer and services developments, thereby ensuring positive impacts on policy actions, for example, that are grounded in the needs of a scientific-local collaboration (Ravnborg and Westermann, 2002).

${ }^{1}$ Docip. Indigenous peoples at the EU. Available online at: https://www.docip.org/ en/indigenous-peoples-at-the-eu/. 
$\mathrm{NbS}$ are inherently dependent on a wide range of stakeholders across disciplines and sectors (Faivre et al., 2017). NbS need to be, by definition, "locally adapted" (European Commission, 2022a), and for successful local adaption to take place, the local community needs to be involved in the design of $\mathrm{NbS}$ from the ground up. $\mathrm{NbS}$ are, as one scholar puts it, all-inclusive; they "... encompass various actions that work with nature in different settings for different goals" (Xie, 2021). Development from the ground-up in $\mathrm{NbS}$ projects allows for diversity and inclusion throughout the processes, ultimately leading to effective policy and local implementations, and stakeholder integration in $\mathrm{NbS}$ projects has been proven to reduce local vulnerabilities from natural disasters (Berghöfer et al., 2008; Saldaña-Zorrilla, 2008; Wamsler et al., 2020).

\section{WHY IS IT IMPORTANT TO INCLUDE WOMEN AND GIRLS?}

As has been drawn attention to at several recent COP conferences, including the recent COP26 (United Nations Climate Change, 2018a,b, 2021a), climate action needs to involve women (United Nations News, 2021). The inclusion of women in $\mathrm{NbS}$ is critical because of the climate change gender gap. Women are disproportionally affected by climate change (UN Women, 2000; United Nations Development Programme, 2016), a fact that was emphasized at COP26 (United Nations News, 2021). In general, women are more than fourteen times more likely to die during a natural disaster than men (UN Women, 2000). Women, according to the 2016 report by the United Nations Development Programme, represent 80 per cent of people displaced by climate change (United Nations Development Programme, 2016). As women are disproportionally affected by climate change, they should be especially involved in the solutions to address climate change, including, not least, the development and implementation of NbS. Their perspectives can help ensure that $\mathrm{NbS}$ are designed and implemented in a way that works for all members of the community-men and women alike-and, therefore, contribute to decreasing the climate change gender gap and achieving SDG 13 (climate action) and SDG 5 (gender equality).

The inclusion of women stakeholders in NbS projects is especially critical for the local adaption of $\mathrm{NbS}$. As stated above, NbS, by the EC's definition, have to be "locally adapted" (European Commission, 2022a). Women, making up approximately half of the world's population (World Bank, 2020), inherently play a key role in the local adaption of NbS. Moreover, women are specifically important participants in climate change adaption strategies, such as $\mathrm{NbS}$, due to their responsibilities in households and communities and as stewards of natural resources (United Nations Development Programme, 2016). For millennia, women have contributed to the sustainable development of their communities and constantly interact with natural resources and ecosystems - from collecting water to using the land for livestock (United Nations News, 2021). Without women, we cannot have genuine sustainable development, and "Women's issues, needs and contributions should be integrated across the planning and execution cycles of climate change policies and projects" (United Nations Development Programme, 2016, p. 6). Projects on NbS must, therefore, include women.

Although there are some important reports on gender and climate change the academic literature on gender and climate change is quite limited. By funding projects on $\mathrm{NbS}$ that involve women as stakeholders, the EC will help to increase this important body of literature. The academic findings from these projects will help address the pressing questions concerning unequal environmental decision-making processes, something that is problematic in both the Global South and Global North (Arora-Jonsson, 2011).

\section{WHY IS IT IMPORTANT TO INCLUDE INDIGENOUS PEOPLES?}

UNESCO defines local and indigenous knowledge as referring "to the understandings, skills and philosophies developed by societies with long histories of interaction with their natural surroundings" (UNESCO, 2021). Indigenous knowledge has made it possible for communities to survive natural disasters throughout centuries and is more important than ever as we face the significant consequences of climate change (Shaw et al., 2009). It is also especially important to involve indigenous communities because while indigenous peoples and local communities (IPLCs) make up $<5$ percent of the world population, they protect over 80 percent of biodiversity (Xie, 2021). Global recognition of the importance of including the knowledge of indigenous peoples in the fight against climate change is evident in Article 7.5 in the Paris Agreement ${ }^{2}$ (United Nations, 2015). COP26 in 2021 is a more recent example of this global recognition. For the first time in the history of the UN Convention on Climate Change, twenty-eight indigenous peoples, representing the seven UN indigenous socio-cultural regions, were invited to engage directly with government and share their experiences on how to reverse biodiversity loss (United Nations Climate Change, 2021b). However, indigenous activists argue that they are still left out of decision-making and call for a more meaningful engagement. Executive director of indigenous climate action, Eriel Deranger stated in an interview with the Guardian, "Indigenous people are more visible but we're not taken any more seriously; we're romanticized and tokenized" (Lakhani, 2021).

As this paper has highlighted, it is important for the success of $\mathrm{NbS}$ to involve a wide range of stakeholders. The involvement of indigenous communities, however, is even more critical for its success. Due to their close connection to nature, indigenous communities are the first to be affected by climate change (United Nations, 2015). As climate change leads to more extreme weather, indigenous communities are at constant risk for displacement due to, for example, flooding, droughts and fires (Williams, 2012). At the same time, the projected changes in temperature pose an additional threat to the health of indigenous peoples and to their livelihood (Williams, 2012). We use the indigenous peoples in Scandinavia, the Sámi as an example; the rise in

\footnotetext{
${ }^{2}$ Paris agreement, 2017 (2015).
} 
temperature will increase the risk of deceases that can affect both the Sámi people and their reindeer, on which they depend for livelihood. It is also projected that the change in temperature may affect the movement, location, and demography of fish. Fishing is an important part of Sámi culture and is likely to be influenced by climate change (Jaakkola et al., 2018). Jaakkola et al. identifies that livelihood changes can have significant effects on both the physical health and cultural well-being of the Sámi people (2018).

$\mathrm{NbS}$ can have major, positive effects on the challenges faced by indigenous communities, such as the Sámi. However, if not done right, $\mathrm{NbS}$ can also have a significantly negative affect on indigenous peoples. For example, NbS such as protecting areas and forest plantations can both physically and economically displace people and can put restrictions on their livelihood and have negative impact on their culture (Vanclay, 2017). These negative consequences add to the already existing disadvantages faced by indigenous peoples, including violations of human rights, discrimination and poverty (Townsend et al., 2020). Indigenous peoples have, as Townsend et al. identifies, a twin vulnerability where they are vulnerable to both the impact and possible solutions to climate change (Townsend et al., 2020). Therefore, it is important to include indigenous peoples in the whole process of $\mathrm{NbS}$, from the initial discussions to the development and implementation phase.

Due to their close connection to nature, their history and culture, indigenous peoples have valuable knowledge that will contribute to the success of $\mathrm{NbS}$. For millennia, these communities have worked closely with nature to address impacts of a changing climate and while many of these techniques are still being used today, it is only recently that these practices have been given a scientific name (Seddon et al., 2021). For example, in Australia, indigenous fire management practices are a $\mathrm{NbS}$, which could help to reduce the risk of wild fires (Global Fire Monitoring Center, 2020). Researchers and policy makers would benefit tremendously from engaging indigenous stakeholders. They can draw on indigenous peoples' knowledge and competence and use this valuable expertise in both scientific research and in the process of formulating related policies (Seddon et al., 2019). Furthermore, engaging with indigenous peoples and local communities and giving them leadership roles in the process creates the potential for these communities to develop an adaptive capacity, making them able to address future issues (Seddon et al., 2021). Engaging important stakeholders, such as indigenous peoples, needs to happen through the whole process of $\mathrm{NbS}$ - from the design phase to the implementation, management, monitoring and evaluation process. The process should foster ownership and empower the indigenous peoples and local communities (Mercer et al., 2012).

\section{HOW TO IDENTIFY KEY STAKEHOLDERS}

While stakeholder inclusion is critical to the success of research projects, few articles study the actions and processes on how to systematically include stakeholders (Ruangpan et al., 2020). We argue that the first step toward stakeholder inclusion begins with a mapping process. In transdisciplinary research, identifying a wide range of stakeholders prior to concentrating on the research problem will bring diversified views to constructively influence the process from the beginning stage (Leventon et al., 2016; Cowan et al., 2021). It is crucial for researchers to be more explicit about how stakeholders are identified and chosen for a given project in order to understand who has the biggest opportunity to shape research outcomes (Leventon et al., 2016) as well as provide best practice knowledge. Scientific knowledge within a given project is understandably highly involved, however, including varied expertise, such as that of local stakeholders, widens discourses and allows a pathway for those directly involved in a topic to have input (Ravnborg and Westermann, 2002). Participation from the public is increasingly embedded in multi-national environmental policy, as policymakers recognize the need to understand who is affected by the decisions and actions they take and who has the power to influence their outcome (Reed et al., 2009).

Once the type of stakeholders are decided upon, the mapping process can begin. Stakeholder mapping involves visualizing the level of stakeholder importance and involvement within the research project. Understanding the sheer value that a diversified range of beliefs, experiences, and knowledge brings, can help to expedite and create acceptance among communities. However, it is not always clear cut on how to decipher who the best stakeholders are and how to find them. Each case area will have their own important stakeholders, which are identified during the mapping stage where researchers are generally aware of the local case environment and can reach out to numerous contacts to identify missing links.

Future projects must create spaces for voluntarism and stewardship, as well as facilitate conversations and collaborations across different sectors and communities to get stakeholders on board (Xie, 2021). With the stakeholder mapping information, project leaders can better understand who is necessary to prioritize and keep most informed throughout the project duration. This system can either be classified as a top-down or bottom-up approach. The latter method is a stakeholderled approach in which stakeholders classify themselves into larger groups. The former is done by classifying the stakeholders into different matrices in accordance with selected attributes (Wojewnik-Filipkowska et al., 2019). The utilization of stakeholder mapping can reduce project failure and enhance success by having sharpened understandings of stakeholder influence patterns (Walker et al., 2008).

\section{CONCLUSION}

Women and indigenous peoples are two marginalized subgroups impacted by the climate crisis (United Nations Development Programme, 2016; Prior and Heinämäki, 2017) and are important stakeholders to engage in $\mathrm{NbS}$. $\mathrm{NbS}$ are, as the EC highlights, critical for tackling environmental challenges such as fires, floods, hurricanes, landslides, and droughts. While the inclusion of stakeholders is important when it comes to addressing these challenges, governments do not always 
include women and indigenous peoples. Because both groups are disproportionally affected by climate change, they should be involved in solutions to address climate change-solutions such as NbS. Women, specifically, are important stakeholders when it comes to NbS because of their roles in communities. Indigenous peoples have lived close to nature and dealt with changes in climate for millennia and thus have important knowledge of NbS. While NbS can be an effective way of tackling climate change, they can also lead to additional negative consequences for indigenous peoples. To avoid this, indigenous peoples should be engaged in the whole process of NbS from the initial discussions to the final evaluation phase. In this article, we argue that research and innovation projects on $\mathrm{NbS}$ funded under the EU's Horizon Europe programme should actively include both women and indigenous peoples. These

\section{REFERENCES}

Arora-Jonsson, S. (2011). Virtue and vulnerability: discourses on women, gender and climate change. Glob. Environ. Change 21, 744-751. doi: 10.1016/j.gloenvcha.2011.01.005

Berghöfer, A., Wittmer, H., and Rauschmayer, F. (2008). Stakeholder participation in ecosystem-based approaches to fisheries management: a synthesis from European research projects. Marine Policy 32, 243-253. doi: 10.1016/j.marpol.2007.09.014

Chausson, A., Turner, B., Seddon, D., Chabaneix, N., Girardin, C. A. J., Kapos, V., et al. (2020). Mapping the effectiveness of nature-based solutions for climate change adaptation. Glob. Chang. Biol. 26, 6134-6155. doi: 10.1111/gcb. 15310

Commission of the European Communities (1996). "Inventing Tomorrow" Europe's Research at the Service of Its People. Available online at: https://eur-lex. europa.eu/legal-content/EN/TXT/PDF/?uri=CELEX:51996DC0332andqid= 1605775177889 andfrom $=\mathrm{EN}$

Cowan, E., Booth, A. M., Misund, A., Klun, K., Rotter, A., and Tiller, R. (2021). Single-use plastic bans: exploring stakeholder perspectives on best practices for reducing plastic pollution. Environments 8:81.

European Commission (2017). Interim Evaluation of Horizon 2020: Commission Staff Working Document. Available online at: https:/op.europa.eu/en/ publication-detail/-/publication/fad8c173-7e42-11e7-b5c6-01aa75ed71a1/ language-en/format-PDF/source-77918455

European Commission (2021a). Horizon Europe: Strategic Plan 2021-2024. Publications Office.

European Commission (2021b). Horizon Europe Programme Guide. Available online at: https://ec.europa.eu/info/funding-tenders/opportunities/docs/20212027/horizon/guidance/programme-guide_horizon_en.pdf

European Commission (2021c). Questions and Answers on the EU's Arctic Strategy. Available online at: https://ec.europa.eu/commission/presscorner/detail/en/ qanda_21_5164

European Commission (2022a). The EU and Nature-Based Solutions. Available online at: https://ec.europa.eu/info/research-and-innovation/research-area/ environment/nature-based-solutions_en

European Commission (2022b). Nature-Based Solutions Research Policy. Available online at: https://ec.europa.eu/info/research-and-innovation/research-area/ environment/nature-based-solutions/research-policy_en

Faivre, N., Fritz, M., Freitas, T., de Boissezon, B., and Vandewoestijne, S. (2017). Nature-Based solutions in the EU: innovating with nature to address social, economic and environmental challenges. Environ. Res. 159, 509-518. doi: 10.1016/j.envres.2017.08.032

Freeman, R. E. (1984). Strategic Management: A Stakeholder Approach. Pitman.

Global Fire Monitoring Center (2020). How 'Smart' Indigenous Fire Management Could Help the Bushfire Crisis. Available online at: https://gfmc.online/media/ 2020/02-2020/how-smart-indigenous-fire-management-could-help-thebushfire-crisis.html oft-forgotten stakeholder groups are important because they are disproportionately affected by climate change, because they possess critical knowledge, and because of the twin vulnerability faced by indigenous peoples.

\section{DATA AVAILABILITY STATEMENT}

The original contributions presented in the study are included in the article/supplementary material, further inquiries can be directed to the corresponding authors.

\section{AUTHOR CONTRIBUTIONS}

All authors listed have made a substantial, direct, and intellectual contribution to the work and approved it for publication.

Griscom, B. W., Adams, J., Ellis, P. W., Houghton, R. A., Lomax, G., Miteva, D. A., et al. (2017). Natural climate solutions. Proc. Nat. Acad. Sci. U.S.A. 114, 11645-11650. doi: 10.1073/pnas.1710465114

IPCC (2021). Summary for Policymakers. In: Masson Delmotte V, Zhai V, Pirani A, Connors SL, Péan C, Berger S, Caud N, Chen Y, Goldfarb L, Gomis MI, Huang M, Leitzell K, Lonnoy E, Matthews JBR, Maycock TK, Waterfield T, Yelekçi O, Yu R, Zhou B, editors. Climate Change 2021: The Physical Science Basis. Contribution of Working Group I to the Sixth Assessment Report of the Intergovernmental Panel on Climate Change. Cambridge University Press.

IUCN (n.d). Defining Nature-Based Solutions. Available online at: https://www. iucn.org/theme/nature-based-solutions/about

Jaakkola, J. J., Juntunen, S., and Näkkäläjärvi, K. (2018). The holistic effects of climate change on the culture, well-being, and health of the Saami, the only indigenous people in the European Union. Curr. Environ. Health Rep. 5, 401-417. doi: 10.1007/s40572-018-0211-2

Lakhani, N. (2021). 'A Continuation of Colonialism': Indigenous Activists Say Their Voices Are Missing at Cop26. The Guardian. Available online at: https://www. theguardian.com/environment/2021/nov/02/cop26-indigenous-activistsclimate-crisis

Leventon, J., Fleskens, L., Claringbould, H., Schwilch, G., and Hessel, R. (2016). An applied methodology for stakeholder identification in transdisciplinary research. Sustain. Sci. 11, 763-775. doi: 10.1007/s11625-016-0385-1

Mercer, J., Kelman, I., Alfthan, B., and Kurvits, T. (2012). Ecosystembased adaptation to climate change in Caribbean small island developing states: integrating local and external knowledge. Sustainability 4, 1908-1932. doi: $10.3390 /$ su 4081908

Prior, T. L., and Heinämäki, L. (2017). The rights and role of indigenous women in the climate change regime. Arct. Rev. Law Politics 8, 193-221. doi: $10.23865 /$ arctic.v8.901

Ravnborg, H. M., and Westermann, O. (2002). Understanding interdependencies: stakeholder identification and negotiation for collective natural resource management. Agric. Syst. 73, 41-56. doi: 10.1016/S0308-521X(01)00099-3

Reed, M. S., Graves, A., Dandy, N., Posthumus, H., Hubacek, K., Morris, J., et al. (2009). Who's in and why? A typology of stakeholder analysis methods for natural resource management. J. Environ. Manage. 90, 1933-1949. doi: 10.1016/j.jenvman.2009.01.001

Ruangpan, L., Vojinovic, Z., Di Sabatino, S., Leo, L. S., Capobianco, V., Oen, A. M. P., et al. (2020). Nature-based solutions for hydro-meteorological risk reduction: a state-of-the-art review of the research area. Nat. Hazards Earth Syst. Sci. 20, 243-270. doi: 10.5194/nhess-20-243-2020

Saldaña-Zorrilla, S. O. (2008). Stakeholders' views in reducing rural vulnerability to natural disasters in Southern Mexico: hazard exposure and coping and adaptive capacity. Glob. Environ. Change 18, 583-597. doi: 10.1016/j.gloenvcha.2008.09.004

Seddon, N., Sengupta, S., García-Espinosa, M., Irina H., Herr, D., and Rizvi, A. R. (2019). Nature-Based Solutions in Nationally Determined Contributions: Synthesis and Recommendations for Enhancing Climate Ambition and Action 
by 2020. Available online at: https://portals.iucn.org/library/efiles/documents/ 2019-030-En.pdf

Seddon, N., Smith, A., Smith, P., Key, I., Chausson, A., Girardin, C., et al. (2021). Getting the message right on nature-based solutions to climate change. Glob. Chang. Biol. 27, 1518-1546. doi: 10.1111/gcb. 15513

Seifollahi-Aghmiuni, S., Nockrach, M., and Kalantari, Z. (2019). The potential of Wetlands in achieving the sustainable development goals of the 2030 agenda. Water 11, 609. doi: 10.3390/w110 30609

Service of Foreign Policy Instruments (2020). EU Holds Consultations With Indigenous Peoples on Prevention of Discrimination and Protection of Rights. Available online at: https://ec.europa.eu/fpi/eu-holds-consultationsindigenous-peoples-prevention-discrimination-and-protection-rights-202002_en

Shaw, R., Takeuchi, Y., Uy, N., and Sharma, A. (2009). Indigenous Knowledge: Disaster Risk Reduction, Policy Note. Available online at: https://www.unisdr. org/files/8853_IKPolicyNote.pdf

Townsend, J., Moola, F., and Craig, M.-K. (2020). Indigenous peoples are critical to the success of nature-based solutions to climate change. Facets 5, 551-556. doi: 10.1139/facets-2019-0058

UN Women (2000). SDG 13: Take Urgent Action to Combat Climate Change and Its Impacts. Retrieved December 6 from https://www.unwomen.org/en/news/ in-focus/women-and-the-sdgs/sdg-13-climate-action

UNESCO (2021). Local and Indigenous Knowledge Systems (LINKS). UNESCO. Available online at: https://en.unesco.org/links doi: 10.18356/22202293-2021-4-11

United Nations (2015). Climate Change. Available online at: https://www.un.org/ development/desa/indigenouspeoples/climate-change.html

United Nations Climate Change (2018a). COP24 Strengthens Climate Action of Local Communities and Indigenous Peoples. United Nations Framework Convention on Climate Change. Available online at: https://unfccc.int/news/ cop24-strengthens-climate-action-of-local-communities-and-indigenouspeoples

United Nations Climate Change (2018b). Gender at COP 24. United Nations Framework Convention on Climate Change. Available online at: https:// unfccc.int/topics/gender/events-meetings/gender-day-other-events-at-cops/ gender-at-cop- 24

United Nations Climate Change (2021a). COP26 Strengthens Role of Indigenous Experts and Stewardship of Nature. United Nations Framework Convention on Climate Change. Available online at: https://unfccc.int/news/cop26strengthens-role- of-indigenous-experts-and-stewardship-of-nature

United Nations Climate Change (2021b). COP26 Strengthens Role of Indigenous Experts and Stewardship of Nature. United Nations Framework Convention on Climate Change. Available online at: https://unfccc.int/news/cop26strengthens-role-of-indigenous-experts-and-stewardship-of-nature

United Nations Development Programme (2016). Gender and Climate Change: Overview of Linkages Between Gender and Climate Change.
United Nations News (2021). Women Bear the Brunt of the Climate Crisis, COP26 Highlight. Available online at: https://news.un.org/en/story/2021/11/1105322

Vanclay, F. (2017). Principles to gain a social licence to operate for green initiatives and biodiversity projects. Curr. Opin. Environ. Sustain. 29, 48-56. doi: 10.1016/j.cosust.2017.11.003

Walker, D. H., Bourne, L. M., and Shelley, A. (2008). Influence, stakeholder mapping and visualization. Constr. Manage. Econ. 26, 645-658. doi: 10.1080/01446190701882390

Wamsler, C., Wickenberg, B., Hanson, H., Olsson, J. A., Stålhammar, S., Björn, H., et al. (2020). Environmental and climate policy integration: targeted strategies for overcoming barriers to nature-based solutions and climate change adaptation. J. Clean. Prod., 247:119154. doi: 10.1016/j.jclepro.2019.119154

Warin, C., and Delaney, N. (2020). Citizen science and Citizen Engagement. Achievements in Horizon 2020 and Recommendations on the Way Forward. European Commission. Available online at: https://op.europa.eu/en/ publication-detail/-/publication/c30ddc24-cbc6-11ea-adf7-01aa75ed71a1

Williams, J. (2012). The impact of climate change on indigenous people-the implications for the cultural, spiritual, economic and legal rights of indigenous people. Int. J. Hum. Rights 16, 648-688. doi: 10.1080/13642987.2011.632135

Wojewnik-Filipkowska, A., Dziadkiewicz, A., Dryl, W., Dryl, T., and Beben, R. (2019). Obstacles and challenges in applying stakeholder analysis to infrastructure projects: is there a gap between stakeholder theory and practice? J. Prop. Investment Finan. 39, 199-222. doi: 10.1108/JPIF-03-2019-0037

World Bank (2020). Population, Female (\% of Total Population). Available online at: https://data.worldbank.org/indicator/SP.POP.TOTL.FE.ZS

Xie, L. (2021). Valuing Inclusion and Diversity, Embracing Uncertainty: Ways Forward for Nature-based Solutions. The British Academy. Available online at: https://www.thebritishacademy.ac.uk/documents/3526/Valuing-InclusionDiversity-Embracing-Uncertainty.pdf

Conflict of Interest: The authors declare that the research was conducted in the absence of any commercial or financial relationships that could be construed as a potential conflict of interest.

Publisher's Note: All claims expressed in this article are solely those of the authors and do not necessarily represent those of their affiliated organizations, or those of the publisher, the editors and the reviewers. Any product that may be evaluated in this article, or claim that may be made by its manufacturer, is not guaranteed or endorsed by the publisher.

Copyright (c) 2022 Gaspers, Oftebro and Cowan. This is an open-access article distributed under the terms of the Creative Commons Attribution License (CC BY). The use, distribution or reproduction in other forums is permitted, provided the original author(s) and the copyright owner(s) are credited and that the original publication in this journal is cited, in accordance with accepted academic practice. No use, distribution or reproduction is permitted which does not comply with these terms. 